\title{
Transitando de um ensino remoto emergencial para uma educação digital em rede, em tempos de pandemia
}

\author{
Moving from emergency remote teaching to digital education in times of \\ pandemic
}

José António Marques Moreira Universidade Aberta, Portugal jmoreira@uab.pt

Susana Henriques Universidade Aberta, Portugal Susana.Henriques@uab.pt

\author{
Daniela Barros \\ Universidade Aberta, Portugal \\ Daniela.Barros@uab.pt
}

Resumo: A evolução das tecnologias e das redes de comunicação tem provocado mudanças acentuadas na sociedade, impulsionando o nascimento de novos paradigmas, modelos, processos de comunicação educacional e novos cenários de ensino e de aprendizagem. Mas ninguém, nem mesmo os professores que já adotavam ambientes online nas suas práticas, imaginava que seria necessária uma mudança tão rápida e emergencial, de forma quase obrigatória, devido à expansão do coronavírus. $\mathrm{Na}$ realidade, com a chegada abrupta do vírus, as instituições educativas e os professores foram forçados a adotar práticas de ensino a distância, práticas de ensino remoto de emergência, muito diferentes das práticas de uma educação digital em rede de qualidade. Tendo, pois, em consideração esse cenário, o objetivo deste texto é apresentar, resumidamente, os princípios básicos para o design de um ambiente online, relacionado à organização, seleção de recursos, preparação e avaliação de e-atividades de aprendizagem.

Palavras-chave: Educação Digital. Tecnologias Digitais. Ensino Online.

Abstract: The evolution of technologies and communication networks have brought changes in society, driving the birth of new paradigms, models, educational communication processes and new teaching and learning scenarios. But no one, not even teachers who already adopted online environments in their practices, imagined that such a rapid and emergency change would be necessary, almost mandatory, due to the expansion of the coronavirus. In fact, with the abrupt arrival of the virus, educational institutions and teachers were forced to adopt distance learning practices, emergency remote teaching practices, very different from the practices of a quality digital education. Therefore, the goal of this paper is to present, in a resume way, the basic principles for the design of an online environment, whether with regard to its organization, communication, selection of resources, preparation and evaluation of e-learning activities.

Keywords: Digital Education. Digital Technologies. Online Teaching. 


\section{Introdução}

O processo de globalização da economia e da comunicação, a evolução das tecnologias e de uma consciência de mundialização em rede têm provocado mudanças acentuadas na sociedade, impulsionando o nascimento de novos paradigmas, modelos, processos de comunicação educacional e novos cenários de ensino e de aprendizagem digital (GARRISON; ANDERSON, 2005). Mas ninguém, nem mesmo os professores que já adotavam ambientes online nas suas práticas, imaginava que seria necessária uma mudança tão rápida e emergencial, de forma quase obrigatória, devido à expansão do COVID 19.

Com efeito, a suspensão das atividades letivas presenciais, por todo o mundo, gerou a obrigatoriedade dos professores e estudantes migrarem para a realidade online, transferindo e transpondo metodologias e práticas pedagógicas típicas dos territórios físicos de aprendizagem, naquilo que tem sido designado por ensino remoto de emergência. E na realidade, essa foi uma fase importante de transição em que os professores se transformaram em youtubers gravando vídeoaulas e aprenderam a utilizar sistemas de videoconferência, como o Skype, o Google Hangout ou o Zoom e plataformas de aprendizagem, como o Moodle, o Microsoft Teams ou o Google Classroom. No entanto, na maioria dos casos, estas tecnologias foram e estão sendo utilizadas numa perspetiva meramente instrumental, reduzindo as metodologias e as práticas a um ensino apenas transmissivo. É, pois, urgente e necessário transitar deste ensino remoto de emergência, importante numa primeira fase, para uma educação digital em rede de qualidade. Mais do que a transferência de práticas presenciais urge agora criar modelos de aprendizagem virtuais que incorporem processos de desconstrução e que promovam ambientes de aprendizagem colaborativos e construtivistas nas plataformas escolhidas (MONTEIRO; MOREIRA; ALMEIDA, 2012; MOREIRA, 2012; MOREIRA, 2018).

Mas como proceder então para realizar esta transição? Como se deve desenhar um ambiente online de aprendizagem? Como devem ser organizadas e planificadas as aulas online? Como se deve comunicar de forma assíncrona e síncrona com o grupo que agora se transformou numa comunidade virtual? Como desenvolver práticas pedagógicas online na realidade digital, sem momentos de presencialidade física? Que tecnologias e plataformas podem ser utilizadas para enriquecer o ambiente de aprendizagem? Como devem ser criadas e desenvolvidas atividades online de aprendizagem? E como se deve avaliar os estudantes nestes cenários virtuais? É a este conjunto de questões que pretendemos responder, apresentando, de forma muito resumida, os princípios básicos para o design de um ambiente online, relacionado, por exemplo, à sua organização, seleção de recursos, ou ainda a em relação à preparação e avaliação de e-atividades de aprendizagem. 


\section{Planificação e organização do ambiente digital em rede}

Como não existe uma sala de aula física para fornecer aos estudantes as informações e orientações que, normalmente, se fazem no início das atividades letivas, é muito importante elaborar um plano, por exemplo, um Guia Pedagógico Semanal (GPS), onde os estudantes possam consultar todas as informações e orientações necessárias para acompanhar as aulas online, informações e orientações necessárias para acompanhar as aulas online (MONTEIRO; MOREIRA; LENCASTRE, 2015).

A definição das estratégias a serem desenvolvidas, o delinear das principais atividades e a seleção dos recursos didáticos mais adequados, tendo sempre presente as competências a serem desenvolvidas nos estudantes, serão as principais etapas a considerar na prossecução de qualquer GPS.

O GPS deve informar os alunos sobre o que se vai aprender, de que forma será feita a aprendizagem, quais serão as estratégias e atividades a desenvolver e qual o produto concreto dessas atividades.

O GPS deve, ainda, possuir uma correta articulação horizontal entre todos os seus elementos e uma articulação vertical ou sequencial inteligível, sendo que não existe um "modelo único" de GPS, cada professor deve "guiar" de acordo com a sua concepção pedagógica e de acordo com as características dos seus estudantes. O mais importante num guia pedagógico é que ele seja funcional para aquele que o realiza (MONTEIRO; MOREIRA; LENCASTRE, 2015).

É muito importante que o professor habitue os estudantes, antes de começarem qualquer tipo de atividade, seja individual ou em grupo, a lerem o GPS na sua totalidade, para que tenham uma visão global de tudo o que há a fazer e possam, a partir daí, programar as atividades que pretendem também desenvolver.

É, igualmente, importante que, quando da criação do GPS, se defina o cronograma das atividades e se configure o ambiente virtual por semanas ou tópicos, definindo o período para o desenvolvimento de cada atividade, selecionando os recursos para a sua execução, com sessões síncronas e assíncronas e com momentos para a avaliação.

É muito útil para o estudante associar a cada unidade os conteúdos, recursos e ferramentas necessários para realizar as atividades. Para além disso é importante ajudar os estudantes a priorizarem e sequenciarem tarefas, propondo-lhes, por exemplo, um número de dias e horas aproximado de dedicação às diferentes fases da atividade apresentada em cada unidade. 
Estas indicações são fundamentais para desenvolver processos de autorregulação e de autonomia nos estudantes e para uma navegação sem sobressaltos no ambiente digital. Para reforçar esta orientação na navegação é também útil criar um espaço de comunicação assíncrona, um quadro de avisos e notícias no tópico inicial do ambiente, onde o professor possa colocar informação acerca de uma determinada atividade que irá iniciar.

\section{Comunicação no ambiente digital em rede}

A virtualização dos sistemas educativos a que neste momento estamos sendo obrigados a efetuar pressupõe a alteração dos seus modelos e práticas e "obriga" o professor a assumir novos papéis, comunicando de formas com as quais não estava habituado.

O professor, mais do que transmitir conhecimentos, deve agora guiar o processo de aprendizagem do estudante de forma a desenvolver as suas capacidades, nomeadamente de aprender a aprender, da sua autoaprendizagem e da sua autonomia. O professor deve acompanhar, motivar, dialogar, ser líder e mediador, fomentando e mediando uma interação humana positiva (GOULÃO, 2012). Espera-se, ainda, que seja moderador, nas relações interpessoais e intrapessoais e faça o seu papel de auto e hetero-avaliador, de conteúdos e desempenhos. Espera-se também que sirva de suporte e estímulo aos estudantes, regulando e orientando as suas emoções, afetos e atitudes DIAS, 2008).

No professor recaem, pois, as funções de motivador, de criador de recursos digitais, de avaliador de aprendizagens e de dinamizador de grupos e interações online. E para ser esse dinamizador é necessário compreender as especificidades dos canais e da comunicação online, síncrona e assíncrona (SALMON, 2000).

É, pois, fundamental criar uma boa estrutura de comunicação para gerar uma autêntica comunidade virtual de aprendiragem, onde o estudante se sinta conectado e motivado. É necessário comunicar com regularidade com os estudantes nos diferentes canais de comunicação para que eles sintam a presença do professor e dos seus pares. Uma sala de aula virtual vazia é uma experiência "cinzenta" para o estudante, uma sala sem vida, sem presença social e cognitiva rapidamente se torna num espaço "sem vida" (MOREIRA; FERREIRA; ALMEIDA, 2013).

As salas de aula virtuais de comunicação assíncrona, normalmente conhecidas por "fóruns" são fundamentais e respondem à essência da educação digital em rede, já que não requerem uma confluência do professor e de seus estudantes no espaço e no tempo, proporcionando a flexibilidade que caracteriza este modelo educativo. No entanto, para que estas salas de aulas sejam 
uma poderosa ferramenta de comunicação é essencial que estejam bem organizadas e estruturadas e que toda a comunidade conheça suas regras operacionais e as siga (GOULÃO, 2012).

É recomendável que no ambiente virtual exista pelo menos um espaço de comunicação para as notícias e avisos; um espaço para as dúvidas que os estudantes possuam; um espaço informal onde os estudantes possam interagir de forma mais descontraída; e diferentes espaços criados em cada tópico para as atividades que se possam desenvolver em cada tema.

Para além dos espaços de comunicação assíncrona, as plataformas, normalmente, também possuem ferramentas de comunicação instantânea incorporadas, como o BigBlueButton na Moodle, embora os estudantes, geralmente, prefiram se comunicar através de ferramentas de comunicação mais informais, como, por exemplo, o WhatsApp. As ferramentas de comunicação, como as webconferências, permitem a comunicação sincrônica com visualização dos utilizadores, o que possibilita uma multiplicidade de aplicações diferenciadas.

\section{Seleção das tecnologias e conteúdos digitais}

Apesar das vantagens que representam, as tecnologias digitais carecem de uma quase permanente formação, porque nessa área, a inovação acontece a todo o momento, o que por vezes proporciona mudanças significativas nas práticas dos professores (MOREIRA; MONTEIRO, 2012).

É necessário conhecer os softwares, perceber o que se pretende com a sua utilização do ponto de vista pedagógico e perceber se o recurso é o mais adequado para o efeito, porque na realidade o simples uso de interfaces digitais não garante, só por si, avanços ou inovações nas práticas educativas (MOREIRA; MONTEIRO, 2015). Muitas interfaces da web social são subutilizadas quando os referenciais adotados ainda replicam práticas adquiridas na web 1.0. Por isso, e sendo a educação digital em rede um processo que se caracteriza pela utilização de tecnologias digitais da web social, é necessário promover práticas pedagógico-didáticas ativas e construtivistas, que sustentem um conhecimento coletivo e uma aprendizagem colaborativa.

A educação em rede, pela sua natureza, é um processo que requer o envolvimento profundo dos diferentes atores que nela participam, quer na definição dos objetivos e percursos de aprendizagem da comunidade, quer também nas relações de proximidade construídas nas colaborações entre pares que sustentam os processos de inovação e criação do novo conhecimento. E para a construção coletiva deste novo conhecimento, tem sido determinante o rápido crescimento, por exemplo, dos Recursos Educacionais Abertos (REA), que têm promovido o acesso e o uso livre de conteúdos e tecnologias (GOULÃO; BARROS, 2014). Estes REAs 
existentes na web são uma fonte inesgotável de recursos digitais que se podem vincular às atividades, quer para apresentar conteúdos, quer para enriquecê-las. No caso de vídeos há plataformas que permitem a sua incorporação através do código embebido, como é o caso do Youtube ou o Vimeo.

\subsection{Recursos digitais e tecnologias audiovisuais}

Estes recursos de aprendizagem são, de fato, um elemento central e muito importante nesta equação, porque a sua utilização em contextos virtuais de aprendizagem, permitem congregar todas as vertentes da literacia, podendo, pois, revelar-se uma opção bastante válida e eficaz.

Com o crescimento do fenómeno dos vídeos baseados na web, tornou-se bastante acessível capturar, editar e partilhar pequenos vídeos, utilizando equipamentos pouco dispendiosos e softwares gratuitos e livres. Muitas instituições de ensino e professores já começam a disponibilizar estes vídeos online, devido à facilidade de integração em ambientes virtuais de aprendizagem.

Nunca antes foi tão fácil produzir e distribuir vídeos online existindo, hoje, uma grande variedade de ferramentas na web disponíveis para assistir, partilhar e editar vídeos. Um exemplo é o Technology Entertainment Design (TED) que inclui muitos recursos, entre os quais o TED Talks, vídeos inspiradores cada vez mais utilizados no campo educacional.

Para além do exemplo anterior existe também a Khan Academy, organização sem fins lucrativos, criada em setembro de 2006 por Salman Khan, que disponibiliza, atualmente, mais de 3000 aulas em vídeo acompanhadas de exercícios para diferentes disciplinas.

O "lar" dos vídeos online mais conhecido em todo o mundo é, sem dúvida, o Youtube. Este serviço permite ao utilizador publicar, ver e partilhar vídeos da sua autoria, ou de outros utilizadores. Existem inúmeros canais no YouTube com conteúdos educativos, como é o caso, por exemplo, do Discovery Channel ou o History Channel. Várias instituições de ensino superior já disponibilizam no YouTube as suas aulas, como The Open University, Yale, Stanford, o MIT entre outras.

Recentemente, o YouTube tem disponibilizado serviços para as escolas e professores que reúnem conteúdos educativos, como YouTube Teachers (https://www.youtube.com/user/teachers) que procura auxiliar os professores a utilizarem pedagogicamente alguns dos seus vídeos.

Existem ainda outros serviços para aceder e partilhar vídeos na web, como o iTunes $U$ que tem uma área específica para o ensino não superior; o TeacherTube (http://www.teachertube.com/) uma plataforma para partilha de vídeos de instrução; o Schooltube (http://www.schooltube.com/) 
onde se disponibilizam vídeos de professores e estudantes de diferentes escolas; o Academic Earth (http://academicearth.org/) página que disponibiliza cursos e vídeos online de universidades reconhecidas mundialmente; o Video-Lectures, (http://videolectures.net/) repositório aberto e gratuito de vídeo-aulas; Edutopia, (http://www.edutopia.org/videos) que faculta vídeos para professores do ensino não superior; e o Vimeo, (http:/ / vimeo.com) uma plataforma de visualização de vídeos.

\subsubsection{Professor maker}

Para além da utilização destes recursos disponíveis na web social, é importante, também, que o professor se "atreva" a produzir o seu próprio material audiovisual através de softwares de fácil utilização, que seja um "maker". Um "maker" que produza vídeos curtos que não "cansem" os estudantes, porque na realidade é preferível criar vários vídeos curtos a ter apenas um muito longo. Para além dos já conhecidos softwares, Movie Maker e iMovie, do Windows e da Apple, respetivamente, existem muitas ferramentas online gratuitas para edição e partilha de vídeo.

Outra possibilidade de criar vídeos relaciona-se com a possibilidade de gravar as aulas via web conferência, que podem ser editadas e disponibilizadas aos estudantes para as verem às vezes, quando for necessário.

Estas sessões síncronas são muito úteis, sobretudo, para desenvolver atividades que necessitem de feedback imediato, para promover a participação ativa estudantes ou para avaliar a aquisição dos conhecimentos. Para além disso, com estas plataformas, podem-se desenvolver atividades de tutoria personalizada, usando ferramentas que permitam criar sessões virtuais em espaços individuais.

\section{Preparação de e-atividades}

As atividades referem-se às diferentes ações que os estudantes realizam em interação com os conteúdos e as indicações que lhes são oferecidos. Se essas atividades forem apresentadas, realizadas ou transferidas online poderão ser consideradas e-atividades.

Uma sala de aula online não é um repositório de conteúdos digitais, é um espaço ativo e dinâmico onde os estudantes recebem informações sobre as atividades online que devem realizar, dentro e fora da plataforma, individualmente ou em grupo, exatamente como num ambiente de sala de aula física. 
Para se produzirem e-atividades bem estruturadas, dever-se-á tirar o maior partido possível dos recursos existentes e das tecnologias digitais da web social.

As e-atividades permitem uma aprendizagem online ativa, participativa, individual ou em grupo. São importantes porque empregam princípios úteis para a aprendizagem bem como uma escolha de tecnologias adequadas. As e-atividades estão centradas nos estudantes para que possam contribuir, trabalhar, interpretar e partilhar conhecimento. Estão suportadas pela ideia de que o conhecimento é construído pelos estudantes de forma colaborativa, ativa e participativa (SALMON, 2004).

Em síntese, as e-atividades são orientações detalhadas de como estruturar uma atividade orientadas para contextos online. E podem ser utilizadas para atividades, exercícios, tarefas de formação para o estudante ou como processos de avaliação.

Nesta perspetiva didática, as e-atividades mais adequadas são aquelas que convidam à construção de conhecimento, experimentação e resolução de problemas, em escala individual e grupal, que visam relacionar o conhecimento prévio dos estudantes com os novos conteúdos, estimulando a reflexão e análise do que foi aprendido. Estimulam ainda processos de tomada de decisão, negociação de significados e o uso de ferramentas de comunicação que facilitam a aprendizagem colaborativa (SALMON, 2004).

Existem critérios de qualidade que devemos ter em conta na hora de elaborar uma eatividade numa perspetiva integradora e construtora dos processos de ensino e aprendizagem:

$\checkmark$ Promover no estudante um papel ativo.

$\checkmark$ Ajudar o estudante a elaborar seu próprio conhecimento a partir da interação com outras pessoas (estudantes e professor) e recursos (digitais).

$\checkmark$ Promover a formulação de questões que podem estar sujeitas a investigação.

$\checkmark$ Convidar a expressar, organizar e contrastar o conhecimento e a hipótese inicial dos alunos sobre os objetos de estudo a serem investigados.

$\checkmark$ Estimular a aprendizagem autônoma.

$\checkmark$ Promover o desenvolvimento de projetos de pesquisa para responder a problemas.

$\checkmark$ Promover a exploração de novos conteúdos através de recursos digitais e outras fontes de informação.

$\checkmark$ Estruturar as informações obtidas, incluindo tarefas como resumir, entender, relacionar, concluir, etc. 
$\checkmark$ Estimular a comunicação, discussão ou colaboração com outros participantes no espaço de aprendizagem virtual.

$\checkmark$ Promover a aplicação ou transferência de processos cognitivos em novos cenários e contextos.

$\checkmark$ Refletir de forma metacognitiva sobre o desenvolvimento e os resultados da pesquisa realizada.

\subsection{Como elaborar uma e-atividade?}

Elementos presentes numa atividade em contexto online (e-atividade)

$\checkmark$ Apresentação do Título e subtítulo

$\checkmark$ Descrição da e-atividade (contexto)

$\checkmark$ Objetivos gerais de aprendizagem

$\checkmark$ Disponibilização dos Recursos de Aprendizagem

$\checkmark$ Período de realização

$\checkmark$ Critérios de Avaliação/cotações (qualitativa e/ou quantitativa, contínua e final tipo - exame ou entrega de trabalho/projeto)

$\checkmark$ Descrição do procedimento de entrega de trabalho

$\checkmark$ Natureza de atividade (individual ou em grupo/colaborativa)

$\checkmark$ Apresentação das etapas do desenvolvimento das atividades solicitadas com vista a flexibilizar e melhor na organização

$\checkmark$ O professor deve estar atento para prestar quaisquer esclarecimentos solicitados durante o período de realização com clareza e dinamismo.

$\checkmark$ O trabalho pode ser desenvolvido e apresentado de forma assíncrona ou síncrona, (dependendo da orientação)

$\checkmark$ Exige conhecimento básico na utilização de vários recursos para atividades diversificadas (imagens, áudio, vídeos, livros, fóruns, chat, outras ferramentas de apresentações de trabalhos online interativas, etc)

$\checkmark$ É um processo de interação (professor/conteúdo/estudante) 
Uma e-atividade bem estruturada tem de ser motivadora, envolvente e intencional, promover uma aprendizagem ativa e forte interação e comunicação, ser moderada por um professor, procurar o desenvolvimento de competências importantes para o estudante a que se destina, nortear-se por objetivos bem definidos, estar associada a uma avaliação adequada, que verifique que os objetivos estão sendo cumpridos, estar bem programada em termos dos diferentes ambientes de aprendizagem, do espaço e tempo e ser flexível, ao ponto de se ir adaptando aos resultados decorrentes da própria avaliação (SALMON, 2004).

A estratégia didática em que se assenta o desenvolvimento da e-atividade, deverá apontar no sentido de conseguir que um grupo seja uma verdadeira comunidade virtual de aprendizagem interativa, colaborativa e investigativa. Deve-se, pois, em salas de aula virtuais, socializar o grupo, induzir e moderar a negociação e a partilha de ideias, facilitar o acesso à informação e ao conhecimento e auxiliar no processo de investigação e desenvolvimento do pensamento crítico.

\section{Avaliação digital}

Tal como nas salas de aula presenciais é possível desenvolver processos de avaliação formativa e sumativa, usando as ferramentas apropriadas disponíveis nos ambientes virtuais de aprendizagem (DIAS; OSÓRIO; SILVA, 2008; AMANTE; OLIVEIRA, 2019).

No que diz respeito à avaliação formativa, a variedade de possibilidades para monitorar e avaliar os alunos em ambientes online é muito ampla, sendo que a maioria das plataformas oferecem uma visão geral do progresso dos estudantes, por meio do feedback fornecido e da nota recebida, que fica sempre registada (TINOCA; OLIVEIRA, 2013).

Seja em que ambiente for, analógico ou digital, é importante desenvolver atividades associadas a um plano de avaliação contínua, que permita ao estudante monitorar seu processo de aquisição de conhecimentos e desenvolvimento de competências (NUNES; VILARINHO, 2006).

Também a avaliação sumativa pode ser realizada em ambientes online, quer através de trabalhos que os estudantes carregam na plataforma digital, quer através de testes de avaliação automática ou manual, incluindo exames síncronos, em tempo real.

Para além disso é também possível apresentar e defender trabalhos oralmente por vídeo, através das plataformas de comunicação síncrona. Ou optar por gravações privadas carregadas em serviços de streaming com o envio do link para o professor.

Por fim, é de referir que a avaliação da participação nas salas de aula virtuais (SAV) também é possível fazer, e é desejável que se faça. A avaliação da participação do estudante numa SAV assíncrona tem por objetivo a aferição da qualidade das intervenções e as competências por si 
desenvolvidas, permitindo, por um lado, identificar as áreas que condicionaram o resultado final da formação e, por outro, ajudando a definir estratégias que conduzam a uma melhoria de todo o processo (MONTEIRO; MOREIRA; LENCASTRE, 2015).

No entanto, previamente a qualquer tipo de avaliação qualitativa do desempenho dos estudantes, é necessário informar os estudantes acerca da forma como vai ser realizada a avaliação nestes espaços de comunicação, quais são as dimensões, os parâmetros e os principais indicadores que irão ser considerados na sua avaliação na SAV. Assim estarão melhor preparados para responder aos desafios colocados pelo professor.

O professor nesse processo é um elemento central, porque para dispor de elementos para a avaliação nos diferentes indicadores considerados precisa de dinamizar de forma ativa a discussão. E para isso necessita não só possuir competências de empatia, mas também competências metacomunicativas, que lhe permitam desafiar a forma como os estudantes pensam e imaginam a aprendizagem; e ainda competências de moderação que lhe permitam organizar uma discussão atribuindo funções diversas aos estudantes, tais como “orientador", "mediador", motivador" ou "consolador". A função de moderador neste contexto assume três dimensões e pode ser comparada ao de um líder. Possui uma dimensão organizativa, já que é o professor que define quem faz o quê e quando na SAV; uma dimensão intelectual, que se refere ao conhecimento relevante dos conteúdos; e uma dimensão social, tendo a responsabilidade de assegurar uma boa atmosfera na SAV.

Para que o estudante possa melhorar a sua performance durante o decorrer das aulas é fundamental que o docente vá dando feedback construtivo e exato acerca do seu desempenho. O estudante necessita dele para compreender o seu desempenho. Comentários como "ótimo", "bom" ou "bastante insuficiente" não têm grande utilidade para além de satisfazerem (ou não) o estudante. Através de um feedback de qualidade da parte do docente, e até de outros estudantes, será possível compreender o desempenho com detalhes mais específicos no que diz respeito a alguns dos indicadores considerados. Desta forma, o feedback oferecerá novas possibilidades de escolha, tornando-se assim um feedforward. Enquanto o feedback é principalmente dirigido ao desempenho do momento, o feedforward é direcionado para o que pode ser feito de maneira diferente na próxima intervenção (MONTEIRO; MOREIRA; LENCASTRE, 2015).

\section{Considerações finais}

Como já referimos na introdução deste texto, a nossa intenção foi apresentar, de forma muito resumida, os princípios básicos que um professor deve conhecer para o design de um 
ambiente online, em relação, sobretudo, à sua organização, seleção de recursos, elaboração e avaliação de atividades de aprendizagem online. No entanto, temos plena consciência de que a leitura deste texto não é suficiente para fazer a transição do ensino remoto para a educação digital em rede necessária. É preciso muito mais.

Como sabemos, as mudanças organizacionais são muitas vezes difíceis, e surgem em contextos dolorosos, como é o caso, e implicam enormes desafios institucionais, pessoais e coletivos de adaptação, de mudança e de flexibilidade e inovação.

E esta mudança a que estamos assistindo, de paradigma e de filosofia educacional, exige uma política ativa de formação docente, de apropriação digital (HENRIQUES et al., 2015). Sendo a educação digital em rede, um processo que se caracteriza pela conectividade, rapidez, fluidez, apropriação de recursos abertos é necessário desencadear processos educativos destinados a melhorar e a desenvolver a qualidade profissional dos professores que, claramente, neste momento, foram pegos de surpresa.

É no quadro dessas necessidades em relação à docência online que se devem definir políticas e criar programas de formação e de capacitação para todos os agentes educativos direcionados para o desenvolvimento de projetos de formação e educação digital que permitam realizar uma adequada transição deste ensino remoto emergencial para uma educação digital em rede de qualidade.

\section{Referências}

AMANTE, L.; OLIVEIRA, I. Avaliação e Feedback. Desafios Atuais. Lisboa: Edições UAb, 2019.

DIAS, P. Da e-moderação à mediação colaborativa nas comunidades de aprendizagem, Educação, Formação e Tecnologias, v.1, n. 1, p. 4-10, 2008.

DIAS, P.; OSÓRIO, A. J; SILVA, B. Avaliação Online. Braga: Centro de Competência: Universidade do Minho, 2008.

GARRISON, D.; ANDERSON, T. El e-learning en el siglo XXI. Investigación e práctica. Barcelona: Octaedro, 2005.

GOULÃO, M. F. The use of Forums and collaborative learning: A study case. Procedia - Social and Behavioral Sciences n. 46, p. 672-677, 2012.

GOULÃO, M.F. Ensinar e aprender em ambientes online: Alterações e continuidades na(s) prática(s) docente(s). In: J. A. MOREIRA; A. MONTEIRO (Orgs.) Ensinar e aprender online com tecnologias digitais. Porto: Porto Editora, p.15-30, 2012.

GOULÃO, M. F.; BARROS, D. Recursos educacionais abertos na prática pedagógica: estratégias, estilos e autorregulação da aprendizagem, In: J. A. MOREIRA; D. BARROS; A. 


\section{Dialogia}

MOREIRA, José António Marques; HENRIQUES, Susana; BARROS, Daniela. Transitando de um ensino remoto emergencial para uma educação digital em rede, em tempos de pandemia

MONTEIRO (Orgs.), Educação a distância e eLearning na web social. Santo Tirso: Whitebooks, p.129152, 2014.

HENRIQUES, S.; MOREIRA, J. A.; GOULÃO, M. F.; BARROS, D. Online Training of Trainers from the Open University, Portugal, In: A. M. TEIXEIRA, A. SZUCCS; I. MÁZAR (Eds.). Expanding Learning Scenarios. Conference Proceedings EDEN 2015. Barcelona: European Distance and e-Learning Network \& UOC - Universitat Oberta de Catalunya, p. 798-804, 2015.

MONTEIRO, A.; MOREIRA, J. A.; ALMEIDA, C. Educação online: Pedagogia e aprendiragem em plataformas digitais. Santo Tirso: De Facto Editores, 2012.

MONTEIRO, A.; MOREIRA, J. A.; LENCASTRE, J.A. Blended (e)Learning na Sociedade Digital. Santo Tirso: De Facto Editores, 2015.

MOREIRA, J. A. Novos cenários e modelos de aprendizagem construtivistas em plataformas digitais, In: MONTEIRO, A.; MOREIRA, J. A.; ALMEIDA, A. C. (Orgs.). Educação Online: Pedagogia e Aprendizagem em Plataformas Digitais. Santo Tirso: De Facto Editores, p. 29-46, 2012.

MOREIRA, J. A.; MONTEIRO, A. M. Ensinar e aprender online com tecnologias digitais: abordagens teóricas e metodológicas. Porto: Porto Editora, 2012.

MOREIRA, J. A., \& MONTEIRO, A. Training and Collaborative Tools for Teaching in the Social Web, Revista Diálogo Educacional, v.15, n. 45, p. 379-397, 2015.

MOREIRA, J. A.; FERREIRA, A. G.; ALMEIDA, A. C. Comparing communities of inquiry in higher education students: one for all or one for each? OpenPraxis. Internacional Council for Open and Distance Education, v.5, n. 2, p. 165-178, 2013.

MOREIRA, J. A. Modelos pedagógicos virtuais no contexto das tecnologias digitais. In: D. MILL; G. SANTIAGO; M. SANTOS; D. PINO (Eds.) Educação a Distância. Dimensões da pesquisa, da mediação e da formação. São Paulo: Artesanato Educacional, p. 37-54, 2018.

NUNES, L.; VILARINHO, L. Avaliação da aprendizagem no ensino online. Em busca de novas práticas. In: M. Silva; E. Santos (Orgs.). Avaliação da aprendizagem em educação online. São Paulo: Edições Loyola, p.68-78, 2006.

SALMON, G. E-Moderating. The Key to Teaching and Learning Online. London: Kogan Page, 2000.

SALMON, G. E-actividades. El factor clave para uan formación en línea activa. Barcelona: Editorial UOC, 2004.

TINOCA, L.; OLIVEIRA, I. Formative assessment of teachers in the context of an online learning environment. Teachers and Teaching: Theory and Practice, v.19, n. 2, p. 221-234, 2013. 


\section{Dialogia}

MOREIRA, José António Marques; HENRIQUES, Susana; BARROS, Daniela. Transitando de um ensino remoto emergencial para uma educação digital em rede, em tempos de pandemia

Recebido em: 03 maio 2020/ Aprovado em: 13 maio 2020

\section{Cite como (ABNT NBR 6023:2018)}

MOREIRA, José António Marques; HENRIQUES, Susana; BARROS, Daniela. Transitando de um ensino remoto emergencial para uma educação digital em rede, em tempos de pandemia. Dialogia, São Paulo, n. 34, p. 351-364, jan./abr. 2020. Disponível em:

https://doi.org/10.5585/Dialogia.N34.17123. 